\title{
MODEL PEMBELAJARAN KOOPERATIF PADA MATERI PEMBELAJARAN SEPAK BOLA DI SMA SANTUN UNTAN
}

\author{
Gebi Sutrisno, Ahmad Atiq, Mimi Haetami \\ Program Studi Pendidikan Jasmani FKIP Untan Pontianak \\ Email : gebisutrisno140998@gmail.com
}

\begin{abstract}
The cooperative model is one of the models that is always used as a solution in the learning process, both for students and the teacher itself, so the role and application of cooperative models will become new knowledge for students. At the time of learning soccer material, the problem in this study was that the level of the cooperative model was able to be applied to students when learning soccer at the level of basic soccer technical skills that were SMA Santun Untan. The research method used is a survey method, with a percentage level of the cooperative model in physical education learning, consisting of several indicators and test items. The results showed that there was a level of cooperative model in the soccer material by answering yes 2,149 with a percentage of yes $75 \%$, and 414 with a category of no with a percentage of $2.5 \%$. This means that $100 \%$ of the understanding of the cooperative model of soccer material is absorbed very well and can be used as a vehicle for the next step. From the conclusions, the right advice is the need for knowledge of students to understand the cooperative model so that in the learning process they are able to develop themselves as knowledge insights and applications in the field, especially soccer material. Teachers and students must be able to work together in order to explore and provide mutual reinforcement during learning, according to the needs to be given during learning.
\end{abstract}

Keywords : cooperative learning model in football learning materials

\section{PENDAHULUAN}

Pendidikan jasmani dan kesehatan adalah mata pelajaran yang merupakan bagian dari pendidikan keseluruhan yang dalam proses pembelajarannya mengutamakan aktivitas jasmani dan kebiasaan hidup sehat menuju pada pertumbuhan dengan pengembangan jasmani, mental, dan sosial yang selaras, serasi, dan seimbang, menurut Husdarta (2011: 3) "pendidikan jasmani dan kesehatan pada hakikinya adalah proses pendidikan yang memanfaatkan aktivitas fisik dan kesehatan untuk menghasilkan perubahan holistik dalam kualitas individu, baik dalam hal fisik, mental, serta emosional". Pendidikan jasmani dari hari ke hari dan dari waktu ke waktu selalu menjadi pendidikan yang integral sangat di perlukan oleh setiap siswa dan kemajuan guru, Pendidikan jasmani juga bisa dikatakan sebagai induk dari sebuah pendidikan di mata pelajaran lainnya yang sangat berbeda dari segala hal baik cara berfikir, cara melakukan dan cara mendapatkan ilmu di sektor yang sangat di butuhkan setiap siswa dalam melaksanakan proses kegiatan pembelajaran.

Dalam hal ini pendidikan jasmani adalah salah satu wadah yang digunakan untuk menambah pengetahuan, kemampuan, serta keterampilan dalam diri manusia, sehingga 
dapat berdampak merubah pola pikir, sifat serta gerak yang menuju kearah yang lebih baik.

Pendidikan yang dapat mendukung perubahan keterampilan gerak dan pola pikir adalah pendidikan jasmani, yaitu pendidikan yang selalu menyentuh tiga ranah ketepatan yaitu pendidikan yang mengarah pada kognitif, afektif dan psikomotor yang menjadi sebagai tolak ukur ketika melakukan yang menjadi fundamental bagi setiap manusia, baik secara langsung maupun tidak langsung, dimana dalam pendidikan jasmani peserta didik di ajarkan konsep belajar dan mengembangkan potensi apa yang di miliki oleh setiap manusia itu sendiri dalam proses peningkatan mutu dalam proses pembelajaran pendidikan jasmani.

Pendidikan jasmani salah satunya adalah materi permainan sepak bola yang di sampaikan dari guru ke murid pada saat pembelajaran permainan bola besar sepak bola dimana siswa sudah mengalami sebuah interaksi namun mengalami hambatan hambatan yang belum tentu setiap materi itu di terima dengan mudah, seperti mengalami ketergantungan dari guru atau siswa yang sudah bisa melakukan, di dalam sebuah pendidikan pembelajaran kooperatif muncul karena adanya perkembangan dalam sistem pembelajaran yang ada.

$$
\text { Pembelajaran kooperatif }
$$
menggantikan sistem pembelajaran yang individual. Dimana guru terus memberikan informasi ( guru sebagai pusat ) dan peserta didik hanya mendengarkan, padahal sepak bola tidak hanya mendengar dan melihat melainkan harus mampu melakukan sebuah sesuatu untuk bisa dilihat dari cara bermain melalui teknik dasar baik langsung atau tidak, yang tidak bisa di lakukan secara individu melainkan kerjasama dengan siswa lainnya. Sepak bola saat ini di dunia pendidikan sangat berperan baik di sekolah maupun di luar sekolahan, khususnya pada saat pembelajaran berlangsung siswa dan siswi mengalami keterputusan antara materi yang di sampaikan dengan materi yang akan di terima oleh siswa, siswa selalu mengalami kelemahan dan ketidak nyambungan materi di berikan oleh guru.

Berdasar pengalaman peneliti mengajar di kelas SMA Santun Untan pada saat ppl siswa belum paham bagaimana melakukan materi yang mudah dari guru dan bisa bekerja sama dengan siswa lainnya, pembelajaran pada saat materi sepak bola dalam pembelajaran pendidikan jasmani, guru hanya menyampaikan materi dan siswa menerima lalu melakukan gerakan - gerakan yang diberikan pada siswa dari awal waktu sampai selesai, bahkan siswa tidak kelihatan apa yang di lakukan dengan mudah dan akurat materi yang diterima atau mudah dan sulitnya materi yang diberikan oleh guru, didalam proses pembelajaran materi sepak bola sendiri siswa tidak bisa menunjukan kreatifitas kemajuan yang menyenangkan agar setiap siswa mengalami situasi pembelajaran lebih mudah dan kooperatif.

Siswa tidak memiliki sebuah inovasi, kreativitas hanya menunggu intruksi dari guru dan teman- teman lainnya juga tidak respek tentang pentingya sebuah pembelajaran sepak bola, dengan adanya model kooperatif learning di sebuah proses pembelajaran, maka pembelajaran akan merasa hidup dan berkembang dan memberikan warna yang berbeda karena siswa bisa menanyakan kelemahan siswa lainya.

Dikarenakan guru dan siswa sama sama aktif dan kreatif dalam mengembangkan materi yang di konsepkan oleh guru itu sendiri, begitu juga model kooperatif juga memberikan kesempatan yang besar kepada siswa untuk selalu mencoba dan melakukan apa yang menjadi intruksi oleh guru. 


\section{METODE PENELITIAN}

Survey sebagai salah satu pendekatan penelitian dimana peneliti ingin menemukan tingkat pendapat kepada orang atau sebuah obyek yang mampu mengambarkan hasil yang di inginkan, seperti dalam hal ini peneliti ingin mendapatkan gambaran tingkat model kooperatif dalam materi sepak bola di SMA Santun Untan, dikatakan pendekatan kuantitatif sebab pendekatan yang digunakan di dalam usulan penelitian, proses, hipotesis, turun ke lapangan, analisa data dan kesimpulan data, sampai dengan penulisannya menggunakan aspek pengukuran, perhitungan, rumus dan kepastian data numerik.

Metode penelitian ini merupakan penelitian deskriptitif kuantitatif. "Penelitian deskriptif ditujukan untuk mendeskripsikan suatu keadaan atau fenomena-fenomena apa adanya" (Nana Syaodih Sukmadinata, 2012: 18). Dalam hal ini adalah mengambarkan tingkat model kooperatif dalam materi sepak bola, alasan peneliti mengambil metode deskriptif karena penelitian ini dimaksudkan untuk menyelidiki suatu keadaan sebagaimana adanya berdasarkan data yang dikumpul kan. Mengingat data yang akan dipaparkan dalam penelitian ini adalah merupakan informasi yang terjadi saat sekarang, hal ini berdasarkan fakta dan data yang diperoleh di lapangan.

Metode deskriptif dalam penelitian ini digunakan didasarkan atas pertimbangan. penelitian ini dilakukan pada saat sekarang, dengan masalah-masalah yang bersifat aktual. Selain itu, penelitian ini dimaksudkan untuk memecahkan masalah sebagaimana adanya mengenai objek yang diteliti.

Menurut (Usman Rianse dan abdi, 2011: 115) bahwa " skala Guttman sangat baik untuk meyakinkan peneliti tentang kesatuan dimensi dan sifat atau sikap yang di teliti, skala ini biasa disebut dengan scalogram yang sangat baik untuk meyakinkan hasil mengenai kesatuan dimensi dalam survey model kooperatif dalam materi sepak bola. Angket dalam penelitian ini dibuat dan dikembangkan oleh peneliti sendiri dimana angket tersebut disusun dalam bentuk check list yang berjumlah 50 item pernyataan dimana masingmasing item terdapat 2 pilihan ya dan tidak.

Tabel 1. Skoring Skala Guttman

\begin{tabular}{ccc}
\hline Alternatif jawaban & Skor alternatif jawaban & \\
\cline { 2 - 3 } & Positif & Negatif \\
\hline Ya & 1 & 0 \\
\hline Tidak & 0 & 1 \\
\hline
\end{tabular}

Jawaban dari responden dapat dibuat skor tertinggi "satu" dan skor terendah nol untuk alternatif jawaban dalam kuisioner penyusun menetapkan kategori untuk setiap peryataan positif ya $=1$ dan tidak $=0$, sedangkan kategori setiap jawaban negatif yaitu ya $=0$ dan tidak $=1$, dalam penelitian penyusun mengunakan skala guttman dalam bentuk checklist dengan demikian berharap akan didapatkan jawaban yang tegas megenai data yang di peroleh. 
Bedasarkan kriteria jawaban angket di atas, maka dapat dikemukakan tabel kisi-kisi angket sebagai berikut :

Tabel 2. Model Pembelajaran Kooperatif Pada Materi

Pembelajaran Sepak Bola Di SMA Santun Untan

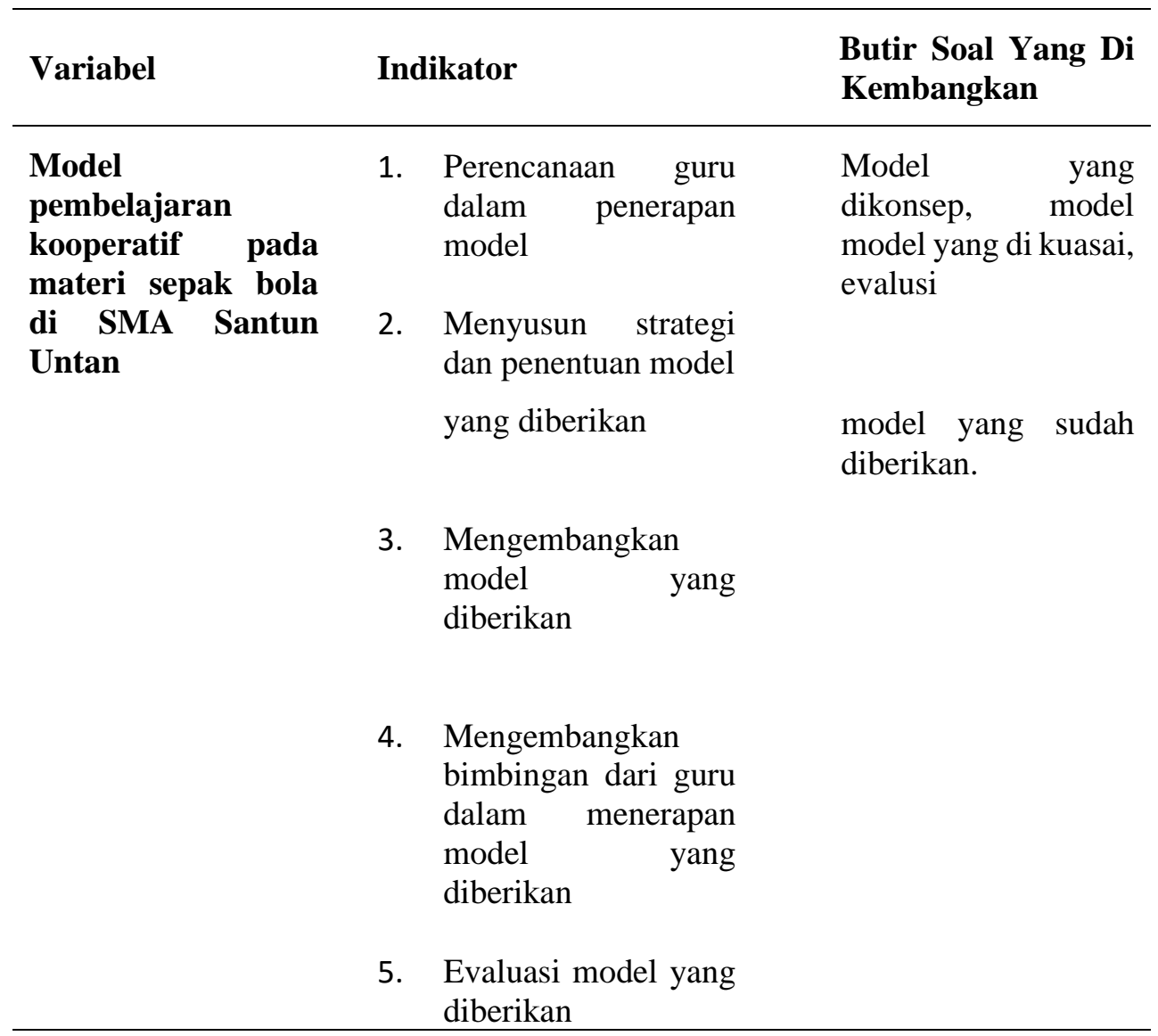

Jumlah

Teknik analisis data merupakan tahap yang penting dan menentukan pada tahap inilah data dikerjakan dan dimanfaatkan hingga sampai berhasil menyimpulkan kebenaran-kebenaran yang dapat dipakai untuk menjawab persoalan-persoalan yang diajukan dalam penelitian. Untuk menjawab presentase peritem soal dan hasil belajar siswa pada mata pelajaran olahraga menggunakan rumus sebagai berikut: 


$$
\begin{aligned}
& \mathrm{P}=\frac{\mathrm{F}}{\mathrm{N}} \times 100 \% \text { Keterangan: } \\
& \mathbf{P}=\text { Persentase } \\
& \mathbf{F} \quad=\text { Frekuensi } \\
& \mathbf{N}=\text { Jumlah responden } \\
& \%=\text { Bilangan tetap (Sudjana, 2001:129) }
\end{aligned}
$$

Sedangkan, untuk menjawab rata-rata persentase keseluruhan model kooperatif dalam materi sepak bola menggunakan rumus sebagai berikut:

$$
\% \text { skor aktual }=\frac{\text { Skor Aktual }}{\text { Skor Ideal }} x 100 \% \text { Sumber: Umi Narimawati (2007: 84). }
$$

\section{HASIL DAN PEMBAHASAN}

HASIL

Dari penelitian yang telah dilakukan di judul model pembelajaran kooperatif pada materi pembelajaran sepak bola di SMA Santun Untan dengan menggunakan angket berjumlah 46 butir soal. Berikut hasil penelitian:

Tabel 3. Hasil Penelitian

\begin{tabular}{lllll}
\hline No & Keterangan & Jumlah & Presentase & Hasil \\
\hline 1 & Tingkat model kooperatif & 2301 & $85 \%$ & IYA \\
\cline { 3 - 5 } & pada materi sepak bola & 459 & $15 \%$ & TIDAK \\
\hline
\end{tabular}

Dari data tabel diatas bahwa hasil penelitian terdapat tingkat model kooperatif pada materi sepak bola dengan menjawab iya 2301 dengan persentasi iya $85 \%$ dan 459 dengan kategori tidak dengan persentasi $15 \%$.

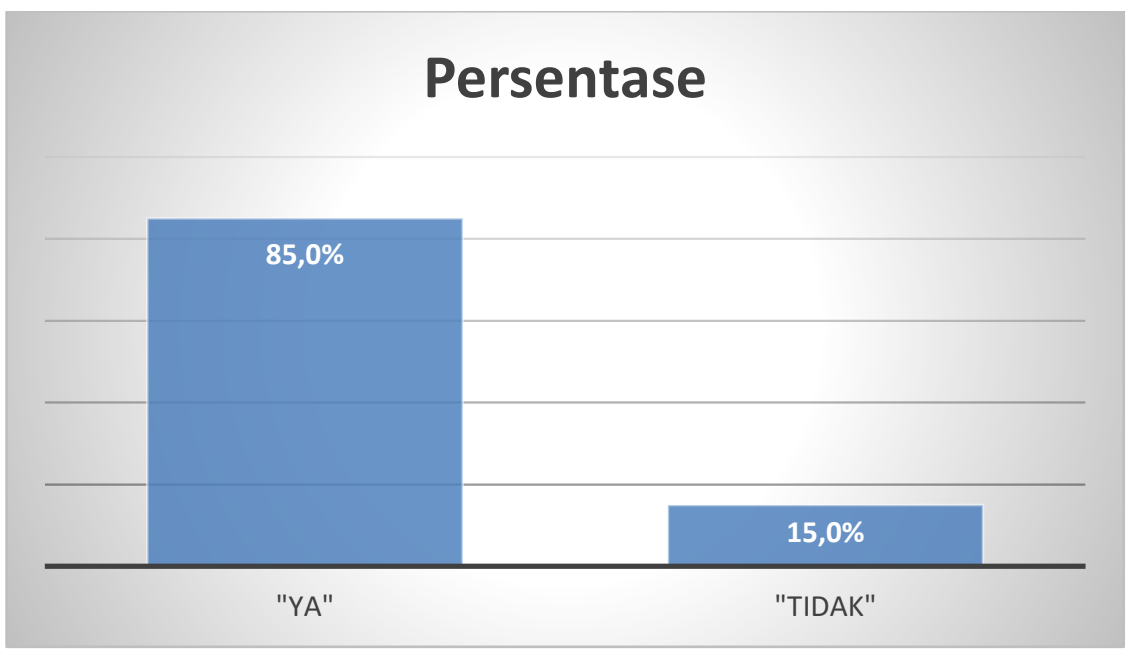

Gambar 1. Tingkat Model Kooperatif Pada Materi Pembelajaran Sepak Bola 
Dari data gambar diatas bahwa hasil penelitian terdapat tingkat model kooperatif materi sepak bola dengan menjawab iya 2.149 dengan persentasi iya $85 \%$ dan 414 dengan kategori tidak dengan persentasi $15 \%$.

\section{PEMBAHASAN}

Penggunaan model pembelajaran kooperatif yaitu siswa dibagi ke dalam kelompok-kelompok belajar yang beranggotakan empat sampai lima orang yang beragam kemampuan dan jenis kelaminnya, kemudian guru memberikan pelajaran dan memastikan bahwa semua siswa-siswa dalam kelompok tersebut memahami pelajaran yang diberikan guru, setelah itu siswa diberikan kuis perseorangan tentang materi yang dipelajari dan tidak diperbolehkan membantu satu sama lain, dengan demikian ada pembiasaan kemandirian kepada siswa untuk percaya diri dalam memecahkan masalah yang dihadapinya, setelah kuis siswa diberikan nilai individu dan penghargaan kelompok. Tentunya hal ini akan mengaktifkan siswa selama proses pembelajaran.

Keunggulan model pembelajaran kooperatif, menjadikan siswa termotivasi untuk belajar sebab tidak ada siswa yang merasa di diskriminasikan, semua siswa bertanggung jawab terhadap skor kelompoknya, serta adanya tutor sebaya antara teman sekelompok. Pada proses pembelajaran, guru memberikan penjelasan materi dengan mengaitkan beberapa contoh dalam kehidupan seharihari. Disini guru memberikan kesempatan kepada setiap peserta didik

\section{KESIMPULAN DAN SARAN Simpulan}

Dari data tabel diatas bahwa hasil penelitian terdapat tingkat model kooperatif materi sepak bola dengan menjawab iya 2301 dengan persentasi iya $85 \%$ dan 459 dengan kategori tidak dengan persentasi $15 \%$ untuk secara langsung terlibat dalam proses belajar yaitu peserta didik mengamati contoh yang diberikan dan selanjutnya guru memberikan kesempatan kepada siswa untuk bertanya tentang permasalahan atau materi.

Pembiasaan kegiatan mengamati dalam pendekatan saintifik ini sangat bermanfaat bagi pemenuhan rasa ingin tahu peserta didik, sedangkan kegiatan menanya bertujuan untuk meningkatkan rasa ingin tahu peserta didik dan melatih siswa untuk berpikir. Kegiatan ini dapat membuat siswa menjadi aktif untuk mencari tahu permasalahan dari contoh yang diberikan oleh guru.

Dengan adanya penelitian kooperatif model pada peserta didik, maka akan memberikan pembaharuan pentingnya model pada saat pembelajaran berlaku khususnya sepak bola, dimana peserta didik di masa seperti ini hanya memerlukan segala sesuatu untuk menjadikan pengetahuan baru yang bisa di aplikasikan sebagai proses pembelajaran kedepannya, bahwa rasa mendidik peserta didik dalam pembelajaran praktik akan menjadi lebih komprehensif dan menjadi program antisipasi untuk situasi apapun, di karenakan peserta didik harus selalu menerima ilmu dari guru dan tanggung jawab sekolah untuk meningkatkan kemampuan baik itu guru maupun peserata didik, assessment menjadi bahan utama dalam rangka apakah setiap guru mampu menilai atau memberikan kontribusinya kepada peserta didik pada saat pembelajaran.

artinya dari $100 \%$ pemahaman model kooperatif materi sepak bola terserap sangat baik dan bisa di jadikan sebagai wahana langkah selanjutnya.

\section{Saran}

Berdasarkan hasil penelitian yang dilaksanakan adapun saran yang dapat diajukan adalah sebagai berikut: 
Pada saat pembelajaran berlangsung khususnya pada saat materi sepak bola perlu di kembangkan dan di berikan strategi dari berbagai model pembelajaran.

Hendaknya peserta didik memiliki peran untuk aktif untuk mengikuti sebuah pembelajaran

\section{DAFTAR RUJUKAN}

Arjanggi, R. (2010). Metode Pembelajaran Tutor Teman Sebaya Meningkatkan Hasil Belajar Berdasar Regulasi-Diri. Semarang. Jurnal Fakultas Psikologi Unissula.

Atiq, A. (2012). Buku Ajar Sepak Bola. Pontianak: Untan Press.

Atiq, A. (2018). Pengembangan Model Latihan Teknik Dasar Sepak Bola Berbasis Bermain Untuk Atlet Pemulausia 8-12 Tahun. Sidoharjo: Zifatama.

Atmasubrata, G. (2012). Serba Tahu Dunia Olahraga. Surabaya: Dafa Publishing.

Ertikanto, C. (2016). Teori Belajar dan Pembelajaran. Jakarta: Media Akademi.

Hamid, S. (2014). Metode Edu Tainment Menjadi Siswa Kreatif dan Nyaman di Kelas. Yogyakarta: DIVA Press.

Huda, M. (2013). Model-model Pengajaran dan Pembelajaran. Yogyakarta: Pustaka Belajar.

Husdarta. (2011). Manajemen Pendidikan Jasmani. Bandung: Alfabeta.

Luxbacher. (2008). Sepak Bola. Solo: Solo Persada Rajawali Perss.

Majid, A. (2013). Strategi Pembelajaran. Bandung: PT Remaja Rosdakarya.

Marliani, N. (2015). Peningkatan Kemampuan Berpikir Kreatif Matematika Model Pembelajaran secara kooperatif dan inovatif agar pengetahuan dan kemampuan peserta didik mudah meningkat.

Peserta didik dan guru harus mampu kolaborasi agar mampu memeberikan suasana pembelajaran yang menyenangkan dan membangun kerjasama kreatifitas dalam meningkatkan pengetahuan.

Missioun Mathematics Project (MMP). Jurnal Formatif.

Mylsidayu, Apta, \& Kurniawan, F. (2015). Ilmu Kepelatihan Olahraga. Bandung: Alfabeta.

Narimawati, U. (2008). Metodologi Penelitian Kualitatif dan Kuantitatif, Teori dan Aplikasi. Bandung: Agung Media.

Nawawi, H. (2010). Manajemen Sumber Daya Manusia untuk Bisnis yang. Yogyakarta: Gajah Mada University Press.

Nugroho. (2009). Pembelajaran Kooperatif Tipe Jigsaw. Bandung: PT. Remaja Rosdakarya.

Rahmani, M. (2014). Buku Super Lengkap Olahraga. Jakarta: Dunia Cerdas.

Rofiq, M. N. (2010). Pembelajaran Kooperatif (Cooperative Learning) Dalam. Falsifa.

Rosdiani, D. (2012). Model Pembelajaran Langsung. Bandung: Alfabeta.

Rusman. (2013). Model-model Pembelajaran: Mengembangkan Profesionalisme. Jakarta: Raja Grafindo Persada.

Salim, A. (2008). Buku Pintar Sepakbola. Bandung: Nuansa.

Sudjana, D. (2001). Metode \& Teknik Pembelajaran Partisipatif. Bandung: Falah Production.

Sugiono. (2015). Metode Penelitian Pendidikan. Bandung: Alfabeta.

Sugiono. (2017). Metode Penelitian Pendidikan. Bandung: Alfabeta.

Suharsimi, A. (2006). Prosedur penelitian suatu pendekatan praktek. Jakarta: Rineka Cipta. 
Suharsimi, A. (2010). Prosedur Penelitian . Jakarta: PT Rineka Cipta.

Sukmadinata, N. S. (2012). Metode Penelitian Pendidikan. Bandung: PT Remaja Rosdakarya.
Suprijono, A. (2013). Cooperative Learning: Teori dan Aplikasi PAIKEM. Yogyakarta: Pustaka Belajar.

Wiarto, G. (2015). Cooperative Learning tipe T GT. Solo: CV Setia Aji. 